\title{
Probabilistic Approach to Predicting Residual Longitudinal Strength of Damaged Double HullVLCC
}

\author{
Van-Vu Huynh*, Seung-Hyun Lee** and Sang-Rai Cho* \\ *School of Naval Architecture and Ocean Engineering, University of Ulsan, Ulsan, Korea \\ **Structure Technology Team, STX Offshore and Shipbuilding, Changwon, Korea
}

KEY WORDS: Damaged ship, Double Hull VLCC, Residual longitudinal strength, Combined bending moment, Monte Carlo simulation

\begin{abstract}
This paper estimates the residual longitudinal strength of a damaged double hull VLCC (Very Large Crude Carrier) under combined vertical and horizontal bending moments using Smith's method. The damage estimated in this study occurred due to collision or grounding accidents. The effects of the randomness of the yield stress, plate thickness, extent of damage, and the combination of these three parameters on the ultimate hull girder strength were investigated. Random variables were generated by a Monte Carlo simulation and applied to the double hull VLCC described by the ISSC (International Ship and Offshore Structures Congress) 2000 report.
\end{abstract}

\section{Introduction}

Damage induced by grounding or collision may decrease the girder resistance of ship hulls. Many studies have estimated the residual longitudinal strength of damaged ships. Paik et al. (1998) developed a fast method for exploring the possibility of hull girder breakage after collision or grounding accidents, and defined the residual strength index, which is based on either the section modulus or the ultimate bending strength. The index was applied to the residual strength assessment of a hypothetical PANAMAX bulk carrier after collision and grounding. It was concluded that the procedure is useful for assessing the reserves and residual strengths of damaged ships.

Gordo and Guedes Soares (2000) considered the ultimate vertical bending moment capacity, while neglecting the effects of the horizontal bending moment, and concluded that the bottom damage exerts much more influence on the hogging moment than on the sagging moment. For a single hull tanker $326 \mathrm{~m}$ in length, a $13 \%$ reduction of the crosssectional area due to damage led to a $7 \%$ loss of the sagging ultimate moment and a $29 \%$ loss in the hogging ultimate moment. For a double hull tanker $168 \mathrm{~m}$ in length, a $9.4 \%$ reduction in the cross-section area led to a $4 \%$ loss in the sagging bending moment and a $14.1 \%$ loss in the hogging bending moment.

Wang et al. (2000) studied the residual strengths of damaged ships. For double hull tankers, they observed a $2.7 \%$ loss of ultimate strength under hogging conditions and a $2.2 \%$ loss under sagging conditions. For bulk carriers they observed a $2.7 \%$ loss of ultimate strength under hogging conditions and a $1.5 \%$ loss in ultimate strength under sagging conditions. For single hull tankers, they observed a $4.5 \%$ loss of ultimate strength under hogging conditions and a $3.9 \%$ loss under sagging conditions.

Wang et al. (2002) reviewed state-of-the-art research on collision and grounding and investigated the longitudinal strengths of ships with damage due to grounding or collision accidents. Wang et al. proposed uniform equations for predicting the residual strengths of damaged hulls, which are functions of ship types that are independent of a ship's principal dimensions.

Qi et al. (2004) studied the residual strength indexes of damaged ship hulls under a vertical bending moment. The residual strength index was reduced by $17 \%$ under sagging conditions for collision damage, and by $2.74 \%$ under hogging conditions for the grounding damage of a bulk carrier under a vertical bending moment. For a naval ship hull that received explosive damage, the residual strength index was reduced by $27.96 \%$ on the lower side under hogging conditions, by $30.76 \%$ on the upper side under sagging conditions, and by $4.55 \%$ at the middle location under hogging conditions and by $4.66 \%$ under sagging conditions.

Fang and Das (2005) assessed the relationship between risk evaluation and structural reliability, and reviewed the evolution of structural reliability applied to ship structures. The ultimate strength lost $50.22 \%$ of its capacity for collision

Corresponding author Sang-Rai Cho: Daehak-ro 93, Nam-gu, Ulsan, 052-259-2163, srcho@ulsan.ac.kr 
damage $(d / D=0.4)$ under hogging conditions and $52.58 \%$ under sagging conditions. For grounding damage $(b / B=0.126)$ the ultimate strengths were reduced by $3.63 \%$ and $0.83 \%$ under hogging and sagging conditions, respectively.

Das and Chuang (2007) investigated residual strength after collision and grounding accidents while considering the residual torsional constant and shear strength, and concluded that damages to the upper side shell and deck structures led to a significant reduction of residual strength when subjected to in-plane compressive load combinations. Luís et al. (2007) studied the longitudinal strength reliability of a grounded SUEZMAX double hull tanker and analyzed different sizes of damage, which extended up to $20 \%$ of the breadth. The strengths of two cases were assessed: when the outer bottom is damaged, and when the inner bottom is also damaged, which was referred to as major damage. The ultimate vertical bending moment was decreased $1.77 \%$ under sagging conditions and $12.01 \%$ under hogging conditions.

Khan and Das (2008) studied the ultimate/residual strengths of the midship sections of a tanker and two bulk carriers under combined vertical and horizontal bending moments in grounding and collision scenarios. The ultimate strength was decreased $0.72 \%$ under sagging conditions for grounding damage and $14.72 \%$ under a horizontal bending moment when the damaged part was in compression due to collision damage.

Hussein and Guedes Soares (2009) studied the residual strengths of three double hull tankers designed according to the new common structural rules (CSR) of the International Association of Classification Societies (IACS). The residual strength index was reduced by $0.9 \%$ for grounding damage to a tanker with $L=264 \mathrm{~m}$, and by $11.6 \%$ for grounding damage to a tanker with $L=320 \mathrm{~m}$.

Cho and Lee (2005) modified the ULSAN program (which was developed by Cho (2001) based on Smith's method (Smith, 1977) to predict the ultimate longitudinal strength of intact ships) to estimate the residual longitudinal strengths of damaged ships under combined vertical and horizontal bending moments.

Most previous studies assumed that the material and geometric properties of ships are deterministic, but these properties may actually be random in nature. Vhanmane and Bhattacharya. (2009) studied the effects of the randomness of yield stress and initial imperfection of a bulk carrier and a tanker to predict the ultimate hull girders strengths of hull girders under a vertical bending moment. The ultimate hull girder strength capacity was estimated through Monte Carlo simulation with 100 samples for each ship.

The present study analyzes the Double Hull VLCC hullgirder described in the ISSC report (2000), the midship

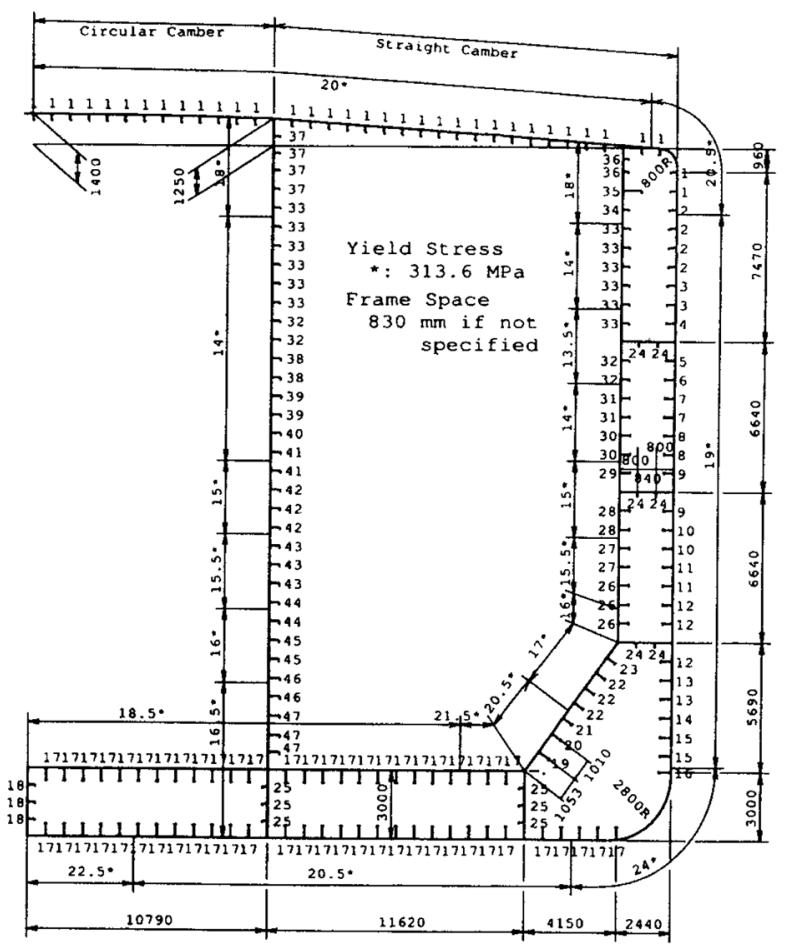

Fig. 1 Midship section of Double Hull VLCC (ISSC, 2000)

section of which is shown in Fig. 1, to predict ultimate longitudinal strength under combined vertical and horizontal bending moments for both intact and damaged conditions using modified ULSAN program. The effects of the randomness of plate thickness, yield stress, the extent of damages, and combinations of these three parameters were considered, and 10,000 samples were generated by Monte Carlo simulation. The residual longitudinal strengths of damaged ships were probabilistically estimated.

\section{Algorithm of modified ULSAN program}

The modified ULSAN program obtains the residual longitudinal strength under the combined vertical and horizontal bending moments for damaged ships. An algorithm of modified ULSAN program is as follows:

Step 1. All elements in damaged area are deleted (see Fig. 2).

Step 2. Assuming the angle of neutral axis $\phi$ relation to the horizontal axis, it is called the instantaneous neutral axis (see Fig. 2).

Step 3. The stress induced in each structural element by the strain is obtained from the average stress-average strain relationship (Cho 2001).

Step 4. The force in each structural element is obtained. When the curvature is increasing, the neutral axis position will shifting upward or downward, that always parallel with instantaneous neutral axis, depending on the equilibrium 
force condition between tensile and compression. In each curvature, recalculate the element strains, forces, total sectional force, and iterate until the total force is zero or less than tolerance.

Step 5. Once the position of the new neutral axis is known, then the correct stress distribution in the structural element is obtained. The vertical bending moment MV respect to horizontal axis $\mathrm{y}$, and horizontal bending moment $\mathrm{MH}$ respect to vertical axis $\mathrm{z}$ (see Fig. 2), about the new neutral axis due to the imposed curvature is then obtained.

Step 6. The residual longitudinal strength is the resultant moment Mcom (or it is called a combined vertical and horizontal bending moments), which direction of heeling angle $\theta$ differ with new neutral axis angle $\phi$ (see Fig. 2), can be obtained by using equation (1) as follows:

$M_{\text {com }}=\sqrt{M_{V}^{2}+M_{H}^{2}}$

In this study, the combined vertical and horizontal bendingmoments are calculated by changing a neutral axis at

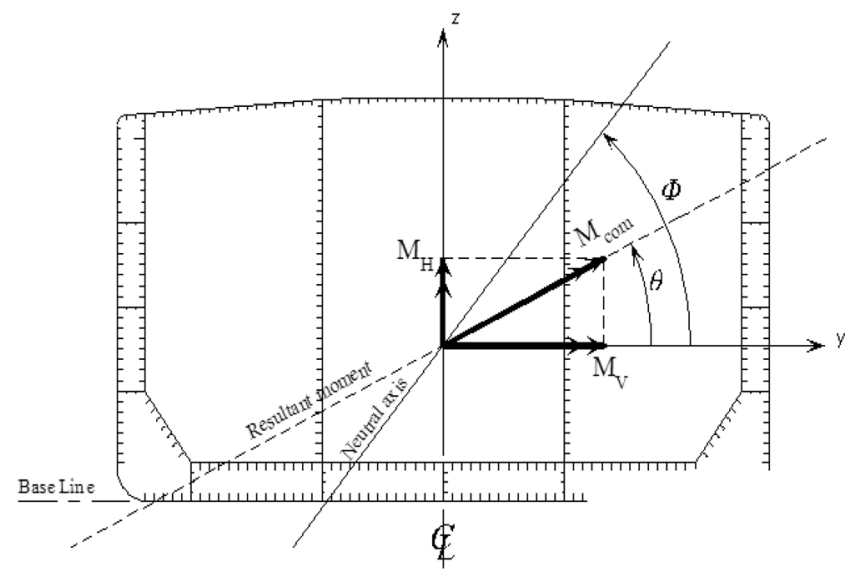

Fig. 2 Direction and location of vertical and horizontal bending moments

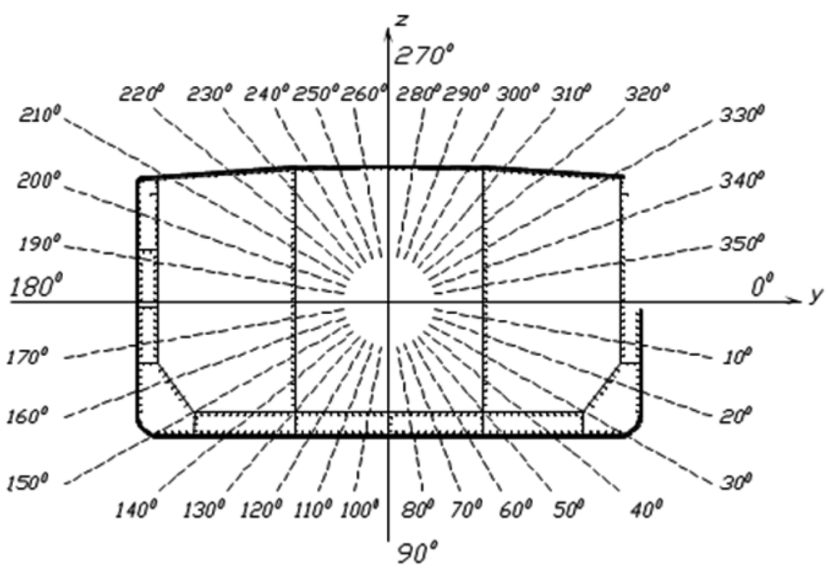

Fig. 3 Angles adopted for the calculation between the horizontal axis and the neutral axis
Table 1 Damage assumed according to ABS (1995a and 1995b)

\begin{tabular}{ccc}
\hline \hline Case & Tankers & Bulk Carriers \\
\hline Collision & 4 meters or $\mathrm{D} / 4$ whichever is greater \\
Grounding & 4 meters or $\mathrm{B} / 6$ whichever is greater \\
\hline
\end{tabular}

a given angle in relation to the horizontal axis. The angle of the neutral axis is vary from 0 o to $360^{\circ}$ in steps of $10^{\circ}$ (see Fig. 3).

\section{Extent of Damages}

Damage due to collision or grounding is most common due to the destruction of a ship structure. In this study, the calculation of collision or grounding damage is performed at mid-ship, and extents of damages are determined according to the American Bureau of Shipping (ABS, 1995a and 1995b), the Det Norske Veritas (DNV, 2008) and the International Convention for the Prevention of Pollution From Ships MARPOL (IMO, 2000) guidelines.

In 1995, ABS published the "Guide for Assessing Hull Girder Residual Strength for Tankers" (July) and the "Guide for Assessing Hull Girder Residual Strength for Bulk Carriers" (November). These guides facilitate and the assessment of structural redundancy and hull-girder residual strength (see Table 1).

In the DNV rules (2008), the following damage conditions are considered independently, using the worst possible positions in each case: for collision with penetration of one ship side, single or double side within a breadth of $\mathrm{B} / 16$; for grounding with penetration of bottom, single or double bottom within a height of $\mathrm{B} / 15$. The extents of damage are given in Table 2.

In Table 3, the extents of damage due to collision and grounding accidents according to MARPOL (IMO, 2000) are provided. Because the bottom damage is small and that was covered by the side damage, therefore this study only applies the side damage of MARPOL for calculation.

\section{Effects of Randomness of Material and Geometric Properties}

The material and geometric properties of ship structures may be random in nature. In this study the plate thickness and yield stress of each structural member (plates, stiffeners, or hard corner), and extent of damage are considered to be uncertainties, while the remaining parameters are considered to be deterministic.

The plate thickness variable is lognormal with the mean taken as an equal nominal value and coefficient of variation 
Table 2 Damage assumed according to DNV (2008)

\begin{tabular}{|c|c|c|c|c|c|}
\hline \multicolumn{3}{|c|}{ Collision } & \multicolumn{3}{|c|}{ Grounding } \\
\hline \multirow{2}{*}{ Damage parameter } & \multicolumn{2}{|c|}{ Damage extent } & \multirow{2}{*}{ Damage parameter- } & \multicolumn{2}{|c|}{ Damage extent } \\
\hline & Single side & Double side & & Single bottom & Double bottom \\
\hline Height: $h / D$ & 0.75 & 0.60 & Height: $b / B$ & 0.75 & 0.55 \\
\hline Length: $l / L$ & 0.10 & 0.10 & Length: $l / L$ & 0.50 & 0.30 \\
\hline
\end{tabular}

$h=$ penetration height

$b=$ penetration breadth

$l=$ penetration length

Table 3 Damage assumed according to MARPOL (IMO, 2000)

\begin{tabular}{|c|c|c|c|}
\hline \multicolumn{2}{|c|}{ Side damage } & \multicolumn{2}{|r|}{ Bottom damage } \\
\hline Transverse extent & $\begin{array}{l}\mathrm{B} / 5 \text { or } 11.5 \text { meters, } \\
\text { whichever is less }\end{array}$ & Transverse extent & $\begin{array}{c}\mathrm{B} / 6 \text { or } 10 \text { meters, whichever is less but } \\
\text { not less than } 5 \text { meters }\end{array}$ \\
\hline Vertical extent & $\begin{array}{l}\text { From the base line upwards } \\
\text { without limit }\end{array}$ & $\begin{array}{l}\text { Vertical extent from } \\
\text { the base line }\end{array}$ & $\mathrm{B} / 15$ or 6 meters, whichever is less \\
\hline
\end{tabular}

(COV) 4\% (Lee and Yang, 1992). The yield stress is also a lognormal distribution with $\mathrm{COV} 8 \%$ and mean of 1.2 times the nominal value (Cheon, 2010). The extent of damages is assumed to be lognormal with the mean shown in Table 4, and four COV values (30\%, $50 \%, 75 \%$ and $100 \%$ ) are considered. All of these random variables are independent.

\section{Monte Carlo simulation}

Several techniques may be used to solve structural probability problems. The Monte Carlo method is a special technique that can be used to generate some results numerically without actually doing and physical testing. The Monte Carlo method is often applied in three situations (Nowak and Collins, 2000):

(1) When solving complex problems for which closed-form solutions are either not possible or extremely difficult.

(2) When solving complex problems that can be solved in closed form if many simplifying assumptions are made. The original problem can be studied without these assumptions, and more realistic results can be obtained.

(3) When checking the results of other solution techniques.

The basis of Monte Carlo simulation procedures are described as follows:

Let $\mathrm{X}$ be a lognormal random variable with mean $\mu_{x}$ and standard deviation $\sigma_{x}$. To generate a sample value $x_{i}$, begin by generating a sample value $u_{i}$ of a uniformly distributed random number such that $0 \leq u_{i} \leq 1$. A sample value $z_{i}$ from a standard normal distribution is then calculated as follows:

$z_{i}=\phi^{1}\left(u_{i}\right)$

where $\phi^{1}$ is the inverse of the standard normal cumulative distribution function.

If $u_{i}$ is less than or equal to 0.5 then:

$z=\Phi^{-1}\left(u_{i}\right)=-t+\frac{c_{0}+c_{1} t+c_{2} t^{2}}{1+d_{1} t+d_{2} t^{2}+d_{3} t^{3}}$

where the coefficients in equation (3) are provied by Nowak and Collins (2000) as follows:

$$
\begin{array}{lll}
t=\sqrt{-\ln \left(u_{i}^{2}\right)} & & \\
c_{0}=2.515517 & c_{1}=0.802853 & c_{2}=0.010328 \\
d_{1}=1.432788 & d_{2}=0.189269 & d_{3}=0.001308
\end{array}
$$

\begin{tabular}{|c|c|c|c|c|c|}
\hline \multicolumn{2}{|c|}{ Case } & \multirow{2}{*}{$\begin{array}{c}\text { Mean damage height } \\
7600\end{array}$} & \multicolumn{2}{|c|}{ Case } & \multirow{2}{*}{$\begin{array}{c}\text { Mean damage breadth } \\
9660\end{array}$} \\
\hline & $1^{*} \mathrm{ABS}$ & & & $1 * \mathrm{ABS}$ & \\
\hline & $2 * A B S$ & 15200 & & $2^{*} \mathrm{ABS}$ & 19330 \\
\hline & $3^{*} \mathrm{ABS}$ & 22800 & & $3^{*} \mathrm{ABS}$ & 29000 \\
\hline \multirow[t]{4}{*}{ Collision } & $0.5^{\star} \mathrm{DNV}$ & 9120 & Grounding & $0.5^{*} \mathrm{DNV}$ & 15950 \\
\hline & $1.0^{*} \mathrm{DNV}$ & 18240 & & $1.0 * \mathrm{DNV}$ & 31900 \\
\hline & $1.5^{\star} \mathrm{DNV}$ & 27360 & & $1.5^{\star} \mathrm{DNV}$ & 47850 \\
\hline & MARPOL & 15200 & & - & - \\
\hline
\end{tabular}

For $u^{i}>0.5, \phi^{1}$ is calculated for $u_{i}^{*}=\left(1-u_{i}\right)$. Then use the

Table 4 Mean value of damage extent parameter (mm) 
following relationship:

$z_{i}=\phi^{1}\left(u_{i}\right)=-\phi^{1}\left(u_{i}^{*}\right)$

Finally, obtain $x_{i}$ using the following equation:

$x i=\exp [\mu \ln X+z i \ln \mathrm{X}]$

where:

$\sigma_{\ln X}=\ln \left[\left(\frac{\sigma_{X}}{\mu_{X}}\right)^{2}+1\right]$

$\mu_{\ln X}=\ln \left(\mu_{X}\right)-\frac{1}{2} \sigma_{\ln X}^{2}$

The residual longitudinal strength in the probabilistic case is generated by Monte Carlo simulation (MCS). The process of MCS is as follows:
(1) Determine the number of simulated values $N=10,000$. The reason to choose the number of simulations $N=10,000$ is to keep the coefficient of variation of the estimate below $10 \%$ (Nowak and Collins, 2000).

(2) Generate $N$ uniform random variables to simulate the plate thickness $u_{t p}$ for each plate, $N$ uniform random variables of yield stress uy for each member element, and $N$ uniform random variables for the extent of collision damage $u_{c}$ and for grounding damage ug.

(3) Generate $N$ values of plate thickness tp, $N$ values of yield stress $\sigma_{Y}$ for member elements, and $N$ values of collision or grounding extents by using equation (5).

(4) Apply the modified ULSAN program to calculate $N$ values of the vertical ultimate bending moment $M_{u v}$, horizontal ultimate bending moment $M_{u h}$, and the ultimate

Table 5 The difference (\%) and COV (\%) of each randomness on residual longitudinal strength

\begin{tabular}{|c|c|c|c|c|c|c|c|c|}
\hline \multirow{2}{*}{ Case } & \multicolumn{2}{|c|}{ Hogging } & \multicolumn{2}{|c|}{ Sagging } & \multicolumn{2}{|c|}{ Compression } & \multicolumn{2}{|c|}{ Tension } \\
\hline & Diff. & $\mathrm{COV}$ & Diff. & $\mathrm{COV}$ & Diff. & $\mathrm{COV}$ & Diff. & $\mathrm{COV}$ \\
\hline I-tp & 0.01 & 0.35 & 0.01 & 0.41 & 0.05 & 0.33 & 0.05 & 0.33 \\
\hline I-yield & -0.25 & 0.96 & 0.11 & 0.86 & 0.10 & 0.65 & 0.10 & 0.65 \\
\hline I-com & -0.23 & 1.03 & 0.12 & 0.95 & 0.12 & 0.72 & 0.12 & 0.72 \\
\hline C-1 ${ }^{*}$ ABS-tp & 5.44 & 0.36 & 6.15 & 0.42 & 4.93 & 0.33 & 3.96 & 0.33 \\
\hline C-1*ABS-yield & 5.13 & 0.96 & 6.17 & 0.89 & 4.94 & 0.64 & 4.01 & 0.65 \\
\hline C-ABS1050-da & 5.41 & 1.50 & 6.05 & 1.45 & 5.06 & 2.05 & 4.20 & 1.83 \\
\hline C-1*ABS-com & 5.16 & 1.86 & 6.11 & 1.73 & 5.15 & 2.20 & 4.22 & 1.93 \\
\hline C-2*ABS-tp & 8.53 & 0.37 & 8.70 & 0.45 & 9.29 & 0.34 & 7.96 & 0.34 \\
\hline C-2*ABS-yield & 8.32 & 1.00 & 8.74 & 0.93 & 9.34 & 0.65 & 7.98 & 0.66 \\
\hline C-ABS2050-da & 7.66 & 1.45 & 8.05 & 1.26 & 9.30 & 4.33 & 7.86 & 3.66 \\
\hline C-2*ABS-com & 7.42 & 1.83 & 8.15 & 1.64 & 9.33 & 4.34 & 7.94 & 3.80 \\
\hline C-DNV-tp & 8.72 & 0.37 & 8.92 & 0.44 & 11.08 & 0.34 & 9.51 & 0.34 \\
\hline C-DNV-yield & 8.52 & 1.02 & 9.00 & 0.92 & 11.14 & 0.65 & 9.53 & 0.65 \\
\hline C-DNV1050-da & 8.19 & 1.24 & 8.51 & 1.05 & 10.92 & 4.77 & 9.34 & 4.06 \\
\hline C-DNV-com & 7.96 & 1.63 & 8.56 & 1.49 & 10.98 & 4.80 & 9.43 & 4.19 \\
\hline C-MARPOL-tp & 24.86 & 0.42 & 24.33 & 0.49 & 45.03 & 0.37 & 42.66 & 0.37 \\
\hline C-MARPOL-yield & 24.63 & 1.13 & 24.38 & 1.01 & 45.11 & 0.69 & 42.81 & 0.76 \\
\hline C-MARPOL-da & 22.42 & 5.02 & 22.23 & 4.36 & 38.93 & 15.20 & 36.40 & 14.79 \\
\hline C-MARPOL-com & 22.14 & 5.02 & 22.29 & 4.49 & 39.19 & 15.32 & 36.58 & 14.89 \\
\hline G-1*ABS-tp & 2.74 & 0.35 & 2.01 & 0.40 & 0.25 & 0.33 & 0.86 & 0.33 \\
\hline G-1*ABS-yield & 2.59 & 0.96 & 2.27 & 0.84 & 0.34 & 0.64 & 0.94 & 0.65 \\
\hline G-ABS1050-da & 2.90 & 1.39 & 2.10 & 1.08 & 0.42 & 0.71 & 1.20 & 1.59 \\
\hline G-1*ABS-com & 2.69 & 1.66 & 2.35 & 1.42 & 0.53 & 1.01 & 1.31 & 1.76 \\
\hline G-2*ABS-tp & 6.01 & 0.36 & 4.81 & 0.40 & 2.86 & 0.34 & 1.21 & 0.34 \\
\hline G-2*ABS-yield & 5.84 & 0.92 & 4.95 & 0.82 & 2.96 & 0.68 & 1.30 & 0.65 \\
\hline G-ABS2050-da & 6.04 & 3.32 & 4.76 & 2.57 & 3.30 & 1.51 & 2.15 & 2.98 \\
\hline G-2*ABS-com & 5.58 & 3.42 & 4.65 & 2.61 & 2.97 & 1.69 & 2.29 & 3.29 \\
\hline G-DNV-tp & 9.99 & 0.36 & 6.49 & 0.42 & 13.44 & 0.37 & 7.50 & 0.32 \\
\hline G-DNV-yield & 9.89 & 0.78 & 6.62 & 0.82 & 13.58 & 0.71 & 7.56 & 0.64 \\
\hline G-DNV1050-da & 10.25 & 7.02 & 7.16 & 5.77 & 13.00 & 2.75 & 8.73 & 3.80 \\
\hline G-DNV-com & 9.62 & 6.82 & 7.22 & 5.75 & 12.32 & 2.85 & 8.19 & 3.82 \\
\hline
\end{tabular}


combined bending moment can be obtained as follows:

$M_{u}=\sqrt{M_{u v}^{2}+M_{u h}^{2}}$

The value of residual longitudinal strength is the mean of the $N$ values of $M_{u}$.

$\mu_{M_{u}}=\frac{\sum_{i=1}^{N}\left(M_{u}\right)_{i}}{N}$

\section{Results and Discussions}

The effects of plate thickness randomness alone, yield stress randomness alone, the extent of damaged randomness alone and of the these three factors combined were calculated. The results for the non-dimensionalized mean value of residual longitudinal strength are shown in Fig. 4, and the difference (\%) of mean value between the damaged and intact cases (in Table 5) or between the random and deterministic cases (in Table 6) and COV (\%) of the residual longitudinal strength is shown in Tables 5 and 6, respectively.

Tables 5 and 6 show that the value at the neutral axis angle is $00,1800,900$, and 2700 , corresponding to hogging or sagging conditions for the vertical bending moment, and the starboard side is in compression or tension for the horizontal bending moment, respectively.

Because there are many simulation cases, each case is denoted by characters as follows:

For effect of each randomness parameter (in Table 5):

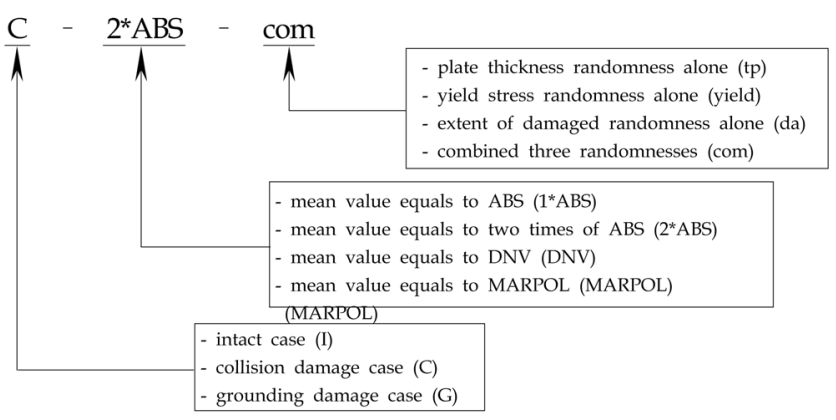

Further explanations with two instances are given here:

If the denotation is C-2*ABS-yield, it means that this is a collision case, mean value is two times the ABS rule assumption, and the randomness of yield stress is considered alone.

If the denotation is I-com, it means that this is the intact case or undamaged case, the extent of damaged variable is deleted, therefore combined of two randomnesses which are plate thickness and yield stress are considered.

For effect of each $\mathrm{COV}$ in the extent of damage randomness alone (in Table 6):

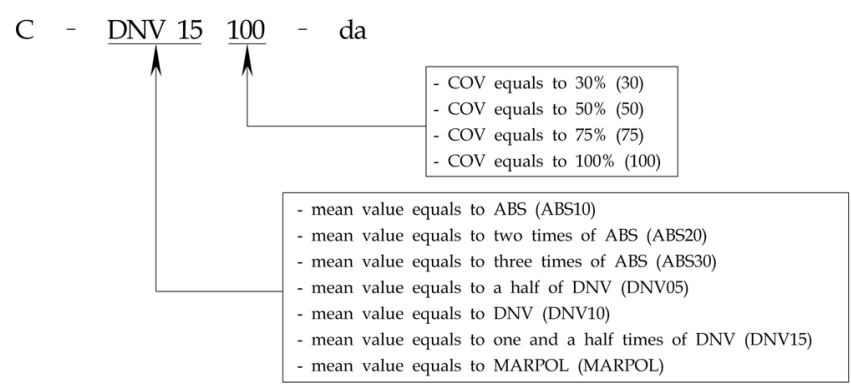

Further explanations with two instances are given here:

If the denotation is G-DNV1575-da, it means that this is the grounding case, mean value is one and a half times the DNV rule assumption, $\mathrm{COV}$ is $75 \%$, and the randomness of extent of damaged is considered alone.

If the denotation is C-MARPOL100-da, it means that this is the collision case, mean value is one time the MARPOL assumption, COV is $100 \%$, and the randomness of extent of damaged is considered alone.

In Fig. 4, the horizontal axis is performed the non-dimensionalized vertical bending moment $\mathrm{Mv} / \mathrm{Mp}$, where $M p$ equal $0.3827 \mathrm{E}+14 \mathrm{Nmm}$ is the fully plastic moment in intact condition, and the vertical axis is the non-dimensionalized horizontal bending moment $\mathrm{Mh} / \mathrm{Mp}$

When considering the randomness of plate thickness alone, the smallest difference of residual longitudinal strength between deterministic and randomness is $0 \%$ in one time of the MARPOL and collision condition, and the largest is 0.45 $\%$ in one time of the ABS and collision condition. The smallest COV is $0.32 \%$ and the largest is $0.49 \%$ in two times of the MARPOL and collision condition.

When considering yield stress randomness alone, the smallest difference is $0.02 \%$ and the largest is $0.78 \%$ in one time of the ABS and collision condition. The smallest COV is $0.64 \%$, and the largest is $1.13 \%$ in one time of the MARPOL and collision condition.

When considering the extent of damage randomness alone, the smallest difference is $0 \%$ in half time and one and a half times of the DNV and collision condition, and the largest is $11.05 \%$ in one time of the MARPOL and collision condition, and $0.03 \%$ and $6.11 \%$ in one and a half times of the DNV and grounding condition. The smallest COV is $0.51 \%$ and the largest is $15.20 \%$ in one time of the MARPOL and collision condition, and $0.19 \%$ and $10.04 \%$ in one and a half times of the DNV and grounding condition.

When considering the three randomnesses factors combined, the smallest difference is $0.02 \%$ and the largest is $10.62 \%$ in one time of the MARPOL and collision condition. 
Table 6 The difference (\%) and COV (\%) of residual longitudinal strength when considering the extent of damage randomness alone

\begin{tabular}{|c|c|c|c|c|c|c|c|c|}
\hline \multirow{2}{*}{ Case } & \multicolumn{2}{|c|}{ Hogging } & \multicolumn{2}{|c|}{ Sagging } & \multicolumn{2}{|c|}{ Compression } & \multicolumn{2}{|c|}{ Tension } \\
\hline & Diff. & $\mathrm{COV}$ & Diff. & $\mathrm{COV}$ & Diff. & $\mathrm{COV}$ & Diff. & $\mathrm{COV}$ \\
\hline C-ABS1030-da & -0.38 & 1.04 & -0.31 & 0.98 & -0.10 & 1.17 & -0.24 & 1.04 \\
\hline C-ABS1050-da & -0.49 & 1.50 & -0.47 & 1.45 & -0.12 & 2.05 & -0.17 & 1.83 \\
\hline C-ABS1075-da & -0.71 & 1.87 & -0.71 & 1.82 & -0.07 & 3.04 & -0.15 & 2.63 \\
\hline C-ABS10100-da & -0.89 & 2.09 & -0.98 & 2.08 & -0.11 & 3.66 & -0.16 & 3.19 \\
\hline C-ABS2030-da & -0.52 & 0.87 & -0.30 & 0.68 & -0.02 & 2.76 & 0.01 & 2.41 \\
\hline C-ABS2050-da & -0.93 & 1.45 & -0.69 & 1.26 & 0.03 & 4.33 & -0.05 & 3.66 \\
\hline C-ABS2075-da & -1.43 & 1.98 & -1.15 & 1.80 & -0.47 & 5.14 & -0.43 & 4.46 \\
\hline C-ABS20100-da & -1.86 & 2.32 & -1.54 & 2.12 & -0.86 & 5.69 & -0.72 & 4.87 \\
\hline C-ABS3030-da & 0.27 & 0.60 & 0.13 & 0.51 & -0.24 & 4.07 & -0.36 & 3.37 \\
\hline C-ABS3050-da & 0.05 & 1.08 & -0.07 & 0.92 & -1.12 & 5.16 & -1.08 & 4.38 \\
\hline C-ABS3075-da & -0.43 & 1.67 & -0.50 & 1.47 & -2.27 & 5.96 & -2.15 & 5.09 \\
\hline C-ABS30100-da & -0.89 & 2.10 & -0.97 & 1.94 & -3.22 & 6.39 & -3.06 & 5.52 \\
\hline C-DNV0530-da & -0.15 & 1.10 & -0.25 & 1.02 & -0.03 & 1.44 & -0.02 & 1.25 \\
\hline C-DNV0550-da & -0.41 & 1.58 & -0.51 & 1.46 & 0.01 & 2.57 & 0.00 & 2.19 \\
\hline C-DNV0575-da & -0.73 & 1.96 & -0.82 & 1.87 & -0.05 & 3.60 & -0.01 & 3.15 \\
\hline C-DNV05100-da & -1.01 & 2.21 & -1.17 & 2.13 & -0.16 & 4.18 & -0.11 & 3.63 \\
\hline C-DNV1030-da & -0.24 & 0.65 & -0.15 & 0.52 & 0.33 & 3.56 & 0.07 & 2.96 \\
\hline C-DNV1050-da & -0.55 & 1.24 & -0.43 & 1.05 & -0.16 & 4.77 & -0.22 & 4.06 \\
\hline C-DNV1075-da & -1.03 & 1.78 & -0.83 & 1.58 & -0.78 & 5.65 & -0.74 & 4.88 \\
\hline C-DNV10100-da & -1.54 & 2.16 & -1.29 & 1.98 & -1.39 & 6.08 & -1.39 & 5.21 \\
\hline C-DNV1530-da & 0.23 & 0.62 & 0.17 & 0.51 & -0.94 & 4.02 & -0.97 & 3.33 \\
\hline C-DNV1550-da & 0.00 & 0.96 & -0.02 & 0.81 & -2.31 & 5.19 & -2.24 & 4.35 \\
\hline C-DNV1575-da & -0.44 & 1.56 & -0.43 & 1.34 & -3.96 & 6.04 & -3.58 & 5.20 \\
\hline C-DNV15100-da & -0.89 & 2.02 & -0.94 & 1.87 & -5.08 & 6.67 & -4.63 & 5.64 \\
\hline C-MARPOL30-da & -1.75 & 3.83 & -1.55 & 3.43 & -5.77 & 11.63 & -5.45 & 11.23 \\
\hline C-MARPOL50-da & -3.25 & 5.02 & -2.76 & 4.36 & -11.05 & 15.20 & -10.93 & 14.79 \\
\hline C-MARPOL75-da & -4.24 & 5.82 & -3.50 & 4.98 & -14.79 & 17.57 & -14.66 & 16.78 \\
\hline C-MARPOL100-da & -4.89 & 6.20 & -3.90 & 5.30 & -17.62 & 18.84 & -17.69 & 18.02 \\
\hline G-ABS1030-da & 0.08 & 0.80 & 0.05 & 0.68 & 0.06 & 0.19 & 0.13 & 0.73 \\
\hline G-ABS1050-da & 0.15 & 1.39 & 0.09 & 1.08 & 0.21 & 0.71 & 0.38 & 1.59 \\
\hline G-ABS1075-da & 0.12 & 1.88 & 0.09 & 1.44 & 0.42 & 1.26 & 0.62 & 2.45 \\
\hline G-ABS10100-da & 0.05 & 2.18 & -0.03 & 1.59 & 0.57 & 1.61 & 0.79 & 3.04 \\
\hline G-ABS2030-da & 0.13 & 2.08 & 0.03 & 1.74 & 0.17 & 0.69 & 0.50 & 1.83 \\
\hline G-ABS2050-da & 0.03 & 3.32 & -0.03 & 2.57 & 0.44 & 1.51 & 0.91 & 2.98 \\
\hline G-ABS2075-da & -0.17 & 4.01 & -0.35 & 3.08 & 0.62 & 1.99 & 1.36 & 3.80 \\
\hline G-ABS20100-da & -0.42 & 4.40 & -0.64 & 3.30 & 0.60 & 2.19 & 1.44 & 4.09 \\
\hline G-ABS3030-da & 0.46 & 3.89 & 0.19 & 3.18 & 0.37 & 1.34 & 0.94 & 2.66 \\
\hline G-ABS3050-da & 0.17 & 5.33 & 0.09 & 4.37 & 0.47 & 2.08 & 1.58 & 3.85 \\
\hline G-ABS3075-da & -0.26 & 6.35 & -0.35 & 5.12 & 0.32 & 2.84 & 1.70 & 4.32 \\
\hline G-ABS30100-da & -0.75 & 6.81 & -0.85 & 5.39 & -0.01 & 3.21 & 1.64 & 4.64 \\
\hline G-DNV0530-da & 0.19 & 1.42 & 0.12 & 0.91 & -0.12 & 1.68 & -0.12 & 0.82 \\
\hline G-DNV0550-da & 0.21 & 2.28 & 0.20 & 1.47 & -0.41 & 2.74 & -0.36 & 1.38 \\
\hline G-DNV0575-da & 0.23 & 3.16 & 0.21 & 2.12 & -0.85 & 4.37 & -0.54 & 2.61 \\
\hline G-DNV05100-da & 0.19 & 3.87 & 0.22 & 2.62 & -0.97 & 6.32 & -0.80 & 3.72 \\
\hline G-DNV1030-da & 0.18 & 4.75 & 0.44 & 3.95 & -0.29 & 1.47 & 0.72 & 2.24 \\
\hline G-DNV1050-da & 0.30 & 7.02 & 0.73 & 5.77 & -0.55 & 2.75 & 1.31 & 3.80 \\
\hline G-DNV1075-da & -0.26 & 8.17 & 0.56 & 6.81 & -1.19 & 3.84 & 1.41 & 4.70 \\
\hline G-DNV10100-da & -0.68 & 8.67 & 0.17 & 7.11 & -1.79 & 4.65 & 1.12 & 5.08 \\
\hline G-DNV1530-da & -0.89 & 6.86 & -0.65 & 6.26 & 1.17 & 2.73 & 0.89 & 5.06 \\
\hline G-DNV1550-da & -2.42 & 8.54 & -2.07 & 7.57 & 0.90 & 3.19 & 0.73 & 5.59 \\
\hline G-DNV1575-da & -4.32 & 9.54 & -3.64 & 8.19 & 0.25 & 3.89 & -0.04 & 5.85 \\
\hline G-DNV15100-da & -6.11 & 10.04 & -4.92 & 8.50 & -0.72 & 4.56 & -0.65 & 6.12 \\
\hline
\end{tabular}




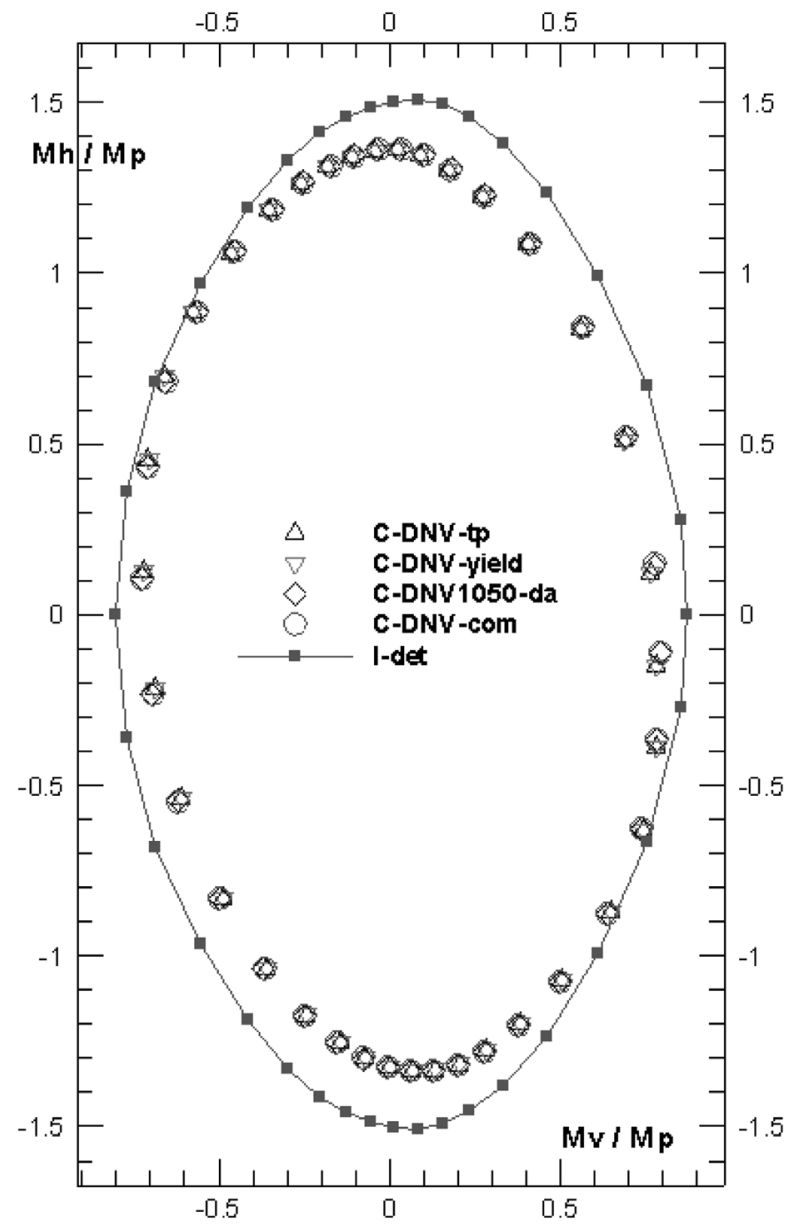

a) Collision condition

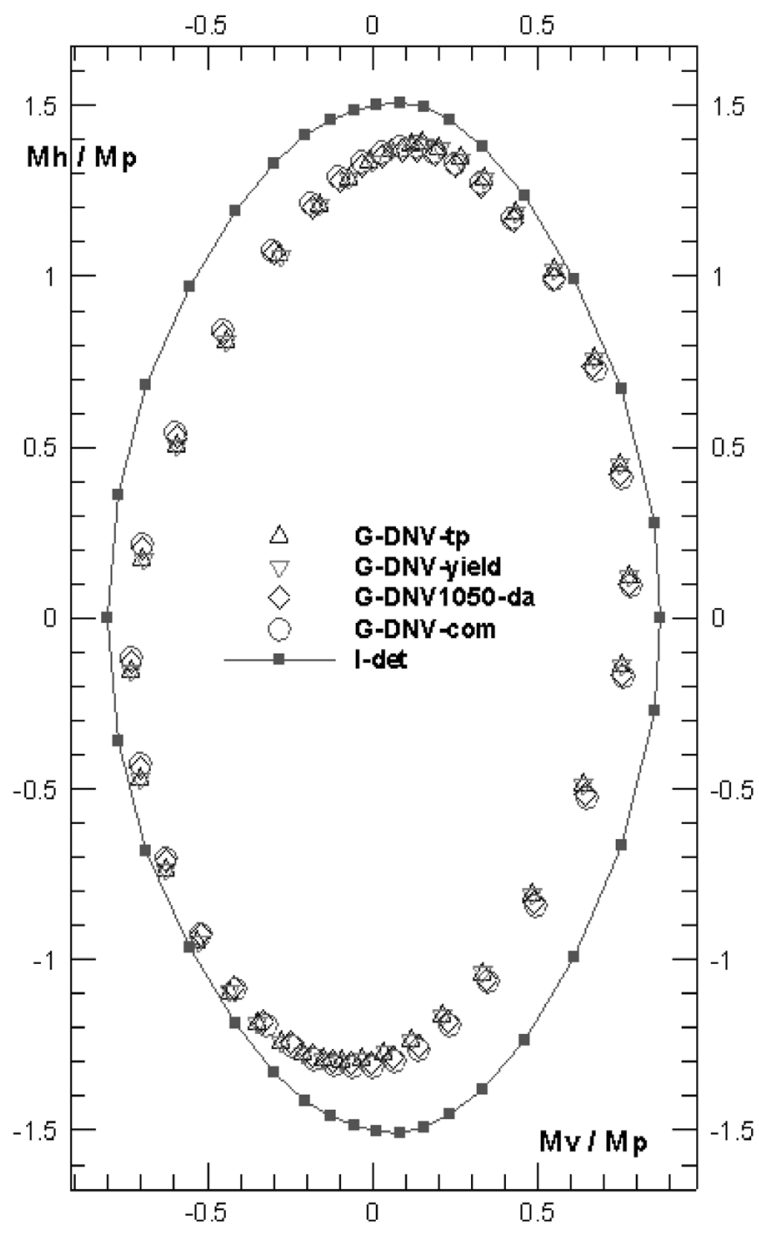

b) Grounding condition

Fig. 4 The effect of each randomness variable on residual longitudinal strength

The smallest COV is $0.71 \%$ and the largest is $15.32 \%$ in one time of the MARPOL and collision condition.

The effect on residual longitudinal strength of the three randomnesses factors combined is largest, and the effect of plate thickness randomness alone is smallest.

By changing the COV from $30 \%$ to $100 \%$ and keeping the mean of the extent of damage randomness variable, the difference and the COV of residual longitudinal strength are almost increasing.

\section{Conclusions}

This work estimated the residual longitudinal strength of a damaged Double Hull VLCC using Smith's method through modified ULSAN program. Estimates were based on the randomness of plate thickness, yield stress, and extent of damage, and the combination of these three parameters of ship hull girders. A Monte Carlo simulation was performed with 10,000 samples to predict the mean, difference, and
COV.

We observed that the residual longitudinal strength exhibits a maximum strength loss according to DNV or MARPOL under hogging (for vertical bending) or compression (for horizontal bending) conditions. The minimum strength loss is expected in the grounding case at compression (for horizontal bending) condition according to ABS.

From Fig. 4, it can be summarized that the non- dimensionalized ultimate longitudinal strength in the intact condition is greater than the others, and that the value is symmetric about a horizontal axis.

For asymmetrical damage, the value of residual longitudinal strength on the lower left (sagging-compression condition) and upper right (hogging-tension condition) of Fig. 4 (which correspond to the angle of the neutral axis between $90^{\circ}$ to $180^{\circ}$ and $270^{\circ}$ to $360^{\circ}$, respectively) are farther from those of the intact condition than the value obtained for the other angles. For the grounding case the opposite effect is observed. Which is similar to the conclusion of Luís et al. 
(2007). Thus, depending on the location of transverse and vertical extents of damage, the behavior of the residual longitudinal strength of damaged ships are differences.

Khan and Das (2008) observed that horizontal loads combined with vertical loads are dangerous from a structural safety perspective. However, the figures in the present study show that the vertical bending moment decreases slightly in the interval from -0.5 to 0.5 of the non-dimensionalized horizontal bending moment. Therefore, the value of residual longitudinal strength changed slightly when the neutral axis angle was small.

We conclude here with a few points about the probabilistic assessment of residual longitudinal strength:

- The behavior of residual longitudinal strength in the probability case was similar to that in the deterministic case.

- The effect of plate thickness randomness alone on residual longitudinal strength is the smallest, and the effect of the three randomnesses factors combined is the largest.

- The effect on residual longitudinal strength of the extent of damage randomness alone is similar to that of the three randomnesses factors combined. Therefore, the effect on residual longitudinal strength of the extent of damage randomness is more dominant than plate thickness alone and yield stress randomness alone.

- Under the same conditions, when increasing the COV of the extent of damage randomness parameter, the residual longitudinal strength also increases.

- Based on the extent of damage assumptions, the value of residual longitudinal strength is largest in the ABS rule and is smallest in the MARPOL rule.

\section{References}

American Bureau of Shipping ABS (1995a). Guide for Assessing Hull-Girder Residual Strength for Tankers, July.

American Bureau of Shipping ABS (1995b). Guide for Assessing Hull-Girder Residual Strength for Bulk Carriers, November.

Cheon, S.G. (2010). Ultimate Strength Assessment for Foundation of Bow Chain stopper, Master Thesis, School of Naval Architecture and Ocean Engineering, University of Ulsan.

Cho, S.R. (2001). Manual of ULSAN Program, School of Naval Architecture and Ocean Engineering, University of Ulsan.

Cho, S.R. and Lee, S.H. (2005). Residual Longitudinal Strength Analysis of Damaged Ships, Proceedings of the Annual Autumn Meeting, SNAK, Yongin, 3-4 November, pp
405-412.

Das, P.K. and Chuang, F. (2007). "Residual Strength and Survivability of Bulk Carriers after Grounding and Collision", Journal of Ship Research, Vol 51, No 2, pp 137-149.

Det Norske Veritas DNV (2008). Hull Structural Design Ships with Length 100 Meters and Above, Part 3 Chapter 1, January.

Fang, C. and Das, P. (2005). Survivability and Reliability of Damaged Ships after Collision and Grounding, Ocean Engineering 32, pp 293-307.

Gordo, J.M. and Guedes Soares, C. (2000). "Residual Strength of Damaged Ship Hulls", Proceedings of 9th IMAM, Napoli, Italy, pp 79-86.

Hussein, A.W. and Guedes Soares, C. (2009). "Reliability and Residual Strength of Double Hull Tankers Designed according to the New IACS Common Structural Rules", Ocean Engineering, doi: 10.1016/j.oceaneng.2009.04.006.

International Maritime Organization IMO, Annex I of MARPOL 73/78, November 2000.

ISSC (2000). "Report of Special Task Committee VI.2 (Ultimate Hull Girder Strength)", Proceedings of 14th ISSC, Nagasaki, Japan, Vol 2, pp 91-321.

Khan, I.A. and Das, P.K. (2008). "Reliability analysis of intact and Damaged Ships considering Combined Vertical and Horizontal Bending Moments", Ships and Offshore Structures, Vol 3, No 4, pp 371-384.

Lee, J.S. and Yang, P.D.C. (1992). "Reliability Assessment against Ultimate Bending Moment of Ships' Hull Girder", Transaction of the Society of Naval Architects of Korea, Vol 29, No 1, March.

Luís, R.M., Hussein, A.W. and Guedes Soares, C. (2007). “On the Effect of Damage to the Ultimate Longitudinal Strength of Double Hull Tankers", Proceeding of 10th Int. Sym. On Practical Design of Ships and Other Floating Structures PRADS, Houston, Texas, USA.

Nowak, A.S. and Collins, K.R. (2000). Reliability of Structures, McGraw-Hill Publisher.

Paik, J.K., Thayamballi, A.K. and Yang, S.H. (1998). “Residual Strength Assessment of Ships after Collision and Grounding", Marine Technology, Vol 35, No 1, pp 38-54.

Qi, E., Cui, W., Wan, Z. and Qiu, Q. (2004). "Study of Residual Strength Index of Damaged Ship Hulls", Journal of Ship Mechanics, Vol 8, No 3, pp 76-84.

Smith, C.S. (1977). "Influence of Local Compressive Failure on Ultimate Longitudinal Strength of Ship's Hull", Proceeding of the International Symposiumon Practical Design in Shipbuilding, Tokyo, pp 73-79.

Vhanmane, S. and Bhattacharya, B. (2009). "Ultimate Strength 
Analysis of Ship Hull Girder Under Random Material and Geometric Properties", Proceeding of the ASME 28th International Conferenceon Ocean, Offshore and Arctic Engineering OMAE, May 31 June 5, Honolulu, Hawaii, USA.

Wang, G., Chen, Y., Zhang, H. and Shin, Y. (2000). "Residual Strength of Damaged Ship Hull", Ship Structures for the New Millennium: Supporting Quality in Shipbuilding, 13, 14 June, Arlington, VA.
Wang, G., Chen, Y., Zhang, H. and Peng, H. (2002). "Longitudinal Strength of Ships with Accidental Damages", Marine Structures 15, pp 119-138.

2011년 5월 19일 원고 접수 2011년 6월 10일 심사 완료 2011년 6월 13일 게재 확정 